\title{
Changes in respiration and the form of the heart-rate CR in dogs'
}

ROBERT D. FITZGERALD AND RICHARD A. WALLOCH UNIVERSITY OF OREGON MEDICAL SCHOOL

The form of the heart-rate $C R$ and respiratory activity in unanesthetized dogs were studied. The form of the CR was principally monophasic-acceleration with amplitude of respiratory correlating with the amount of heart-rate acceleration.

Several studies of cardiac conditioning in humans have shown that when respiration is not controlled the form of the heart-rate CR is diphasic; i.e., acceleration followed by deceleration (cf., Zeaman \& Smith, 1965). Wood \& Obrist (1964) also found that amplitude of respiratory inspiration was positively correlated with the magnitude of the accelerative component of the CR, thus raising the possibility that heart-rate acceleration was an artifact of respiratory activity. The purposes of the present report were to provide data on the form of the heart-rate $C R$ and respiratory activity in unanesthetized dogs.

Subjects and Apparatus

The Ss were 55 experimentally naive mongrel dogs at least two years old. The experiment was conducted in a sound-insulated room. The CS was a 13 sec., 350 cps tone presented at $80 \mathrm{db}$ spl. The US was a $3 \mathrm{sec}$, $9.9 \mathrm{ma}, 60$-cycle, ac shock. The CS-US interval was $10 \mathrm{sec}$. with the US overlapping the final $3 \mathrm{sec}$. of the CS. Respiration was recorded by means of a bellows type pneumograph strapped around S's chest.

\section{Procedure}

A detailed description of the experimental design of the study can be found in an earlier report (Fitzgerald, in press). Briefly, there were four groups of Ss receiving two days of acquisition and two days of extinction. Only the acquisition results will be described here. On the first day of acquisition a $100 \%$ group $(\mathrm{N}=15)$ was given 18 reinforced trials (RT), while two 50\% groups $(\mathrm{N}=15$ in each case) were given $18 \mathrm{RT}$ and 18 nonreinforced trials (NRT) according to a Gellerman order. The remaining group $(\mathrm{N}=10)$ received 18 backward conditioning trials with the US-CS interval varying among 45,60, and $75 \mathrm{sec}$. On the second day of acquisition, $_{9}$ the $100 \%$ group and one of the $50 \%$ groups received an additional $12 \mathrm{RT}$. The remaining $50 \%$ group was given $12 \mathrm{RT}$ and $12 \mathrm{NRT}$. Hereafter, the 100\%, the switched $50 \%$, and the unswitched $50 \%$ groups will be labeled $100-100,50-100$, and $50-50$, respectively. The control group received 12 backward trials on the second day. The mean intertrial interval (ITI) in the $50 \%$ condition was $3.5 \mathrm{~min}$. In the case of $100 \%$ reinforcement, the ITIs exactly matched those obtaining between RT in the $50 \%$ schedule (mean $=6.5$ ).

\section{Response Measures}

The data obtained on each trial of acquisition were quantified as follows:

Heart rate. Beats-per-min. (bpm) measures of heart rate were computed for each of five successive 2-sec. periods of the 10-sec. CS-US interval. On NRT bpm heart-rate levels were determined for the 3-sec.shock period and, after CS termination, for five successive 2-sec. periods followed by two 4-sec. periods. The rates during each of these intervals were then corrected for base level by subtracting the bpm rate during the $10 \mathrm{sec}$. immediately preceding the onset of the CS (pre-CS).

Respiration. Two amplitude measures of respiration similar to those reported by Wood \& Obrist (1964) were employed. They were calculated by first obtaining the amplitude of the largest single inspiration during (1) the first $6 \mathrm{sec}$. of the CS, and (2) during the next 4 sec. of the CS. The average amplitude of the two peaks just prior to the onset of the CS was then subtracted from each of these measures, providing difference scores which were relative to pre-CSbaseline. Results

Heart rate. The heart-rate responses in successive time periods after CS onset averaged over the two days of acquisition are plotted in Fig. 1. This figure shows that the cardiac reactions of the experimental groups during the CS-US interval were mainly accelerative; onlv the 50-50 group showed any appreciable deceleration prior to the US. Following the termination of the CS on NRT, heart rate for the 50-50 group continued to decelerate, reaching the pre-CS level 4 sec. later.

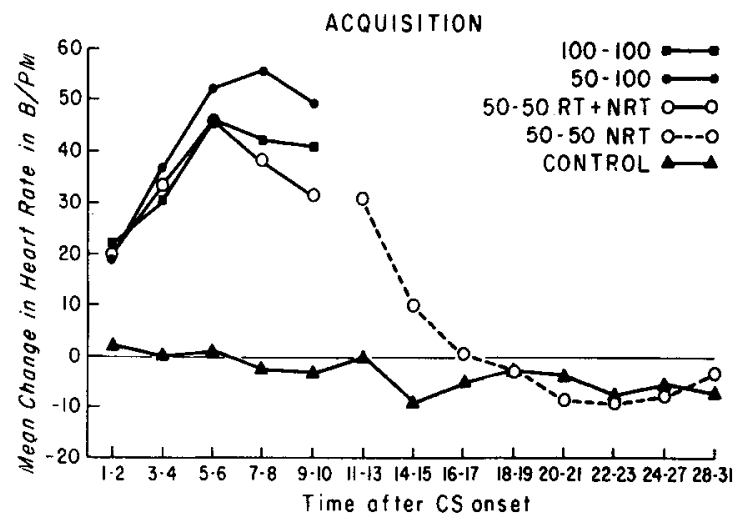

Fig. 1. Heart-rate changes corrected for pre-CS level in successive time periods following CS onset averaged over acquisition. 
Comparable data for the 50-100 group on the first day of conditioning, while not shown, are highly similar to those plotted for the 50-50 group. Separate trend test analyses of variance of the CS-US interval data of each of the experiment groups indicated the presence of significant overall trends $(p<.001$ in each case), with significant linear (at least the .05 level) and quadratic ( $p<.001$ in each case) components. The reliability of the decrease in heart rate prior to US was checked for each group by comparing the 2-sec. period where heart rate was maximum with the $9-10 \mathrm{sec}$. period. The only group showing a significant decrease was the 50-50 $(t=3.19, \mathrm{df}=14, \mathrm{p}<.01)$.

Respiration. Respiration results are based on the data of $10 \mathrm{Ss}$ in the 100-100 group, $12 \mathrm{Ss}$ in the 50-50 group, and $14 \mathrm{Ss}$ in the 50-100 group. Data from the remaining Ss were not obtained because of apparatus failures. Separate $t$ tests indicated that amplitude of respiration was significantly greater for the experimental groups $(p<.02$ in each case) in the first 6 sec. of the CS compared to the last $4 \mathrm{sec}$. of the CS. Rank order correlations between respiration and heart rate during the successive 2-sec. periods of the CS-US interval for the separate groups are shown in Table 1. This table reveals that the highest correlations for the groups tended to occur in the vicinity of their peak heart-rate responses. The possible relationship between the smaller amplitude of respiration in the last 4 sec. of the CS and the decrease in heart rate during this period shown by the 50-50 group was checked by means of a rank order correlation in which the difference in heart-rate between the 5-6 sec. period and the 9-10 sec. period was compared with the difference in maximum amplitude of respiration between the first $6 \mathrm{sec}$. and the last 4 sec. of the CS. This correlation was close to zero, $\mathbf{r}=.03$.

Table 1.

Rank order correlations between maximum amplitude of respiration and heart rate in successive 2 -sec. periods of the CS-US interval.

\begin{tabular}{llllll}
\multicolumn{6}{c}{ Successive 2-sec. periods of the CS-US interval } \\
Groups & $1-2$ & $3-4$ & $5-6$ & $7-8$ & $9-10$ \\
\hline $100-100$ & .48 & $.67^{*}$ & $.64^{* *}$ & $.62^{*}$ & .41 \\
$50-50$ & .33 & $.70^{* *}$ & $.72^{* *}$ & $.19^{*}$ & .20 \\
$50-100$ & $.65^{* *}$ & $.46^{*}$ & $.59^{*}$ & $.85^{* *}$ & $.82^{* *}$ \\
\hline
\end{tabular}

* $P .05$

$*$ * P. 01

\section{Discussion}

Contrary to the diphasic acceleration-deceleration response reported for humans when respiration is not controlled, the form of the heart-rate CR in the present experiment was mainly monophasic-acceleration. Although there was some tendency for deceleration to occur, heart rate did not reach the pre-CS level until $4 \mathrm{sec}$. after the CS terminated. Thus, the deceleration looks like simple recovery from the preceding acceleration (cf., Zeaman \& Smith, 1965). One reason for the discrepancy between the present results and those reported for the human might be that we used a delayed conditioning paradigm, whereas in the human studies, a trace procedure was employed. According to Black et al (1962) a trace procedure is more likely to produce deceleration in curarized dogs than is a delayed procedure.

The respiration results of the present experiment are similar to those reported by Wood \& Obrist (1964) for humans insofar as magnitude of heart-rate acceleration was correlated with amplitude of respiration. There was, however, no correlation between the decrease in heart rate and respiratory activity; a finding that is consistent with the notion mentioned above that the decrease in heart rate was simply a recovery phenomenon. These results suggest that respiration may have affected the magnitude of heart-rate acceleration but that heart-rate deceleration was independent of respiration. In our view, heart rate and respiration are part of a more general conditioned defense reaction, the components of which may interact with one another through established connections in the nervous system.

\section{References}

Black, A. H., Carlson, N. J., \& Solomon, R. L. Exploratory studies of the conditioning of autonomic responses in curarized dogs. Psychol. Monogr., 1962, 5, 76, (Whole No. 348).

Fitzgerald, R. D., Vardaris, R. M., \& Teyler, T. J. The effects of partial reinforcement followed by continuous reinforcement on classically conditioned heart-rate in the dog. J. comp. physiol. Psychol., in press.

Wood, D. M., \& Obrist, P. A. Effects of controlled and uncontrolled respiration on the conditioned heart rate response in humans. J. exp. Psychol., 1964, 68, 221-229.

Zeaman, D., \& Smith, R. W. Review of some recent findings in human cardiac conditioning. In William F. Prokasy (Ed.), Classical conditioning. New York: Meridith Publishing Co., 1965. Pp. 378-418.

\section{Note}

1. This research was supported by Grant HE 06 336-05 from the National Heart Institute, and by Grant GB-2221 from the National Science Foundation. 